Sinela Jurkova*

\title{
Transcultural Competence Model: An Inclusive Path for Communication and Interaction
}

https://doi.org/10.1515/jtc-2021-2008

Published online October 26, 2021

Abstract: The impact of transnational migration and globalization on human society, along with emerging multiple identities, calls for reconceptualization of the meaning of cultural competence and a shift toward transcultural competencea mode of being and learning in which humans communicate and interact among cultures in a very diverse and dynamic environment. Embracing transculturalism perspective calls for integration of new concepts and approaches in communication and education that promote active participation, adaptation, and interaction. To this end, this essay examines the holistic model for developing transcultural competence that involves inquiry, framing, and positionality that challenge our taken-for-granted frames of references and expand our worldviews. The study also explores how educators and learners develop cognitive, emotional, and social qualities, engaging in dialog and critical reflection that informs our actions as the catalyst for positive social change and transformation. Implementing this holistic perspective toward transcultural education can create an inclusive environment for communicating, interacting, and learning without opposing cultural, national, and ethnic binaries.

Keywords: transculturalism, transnationalism, transcultural competence, transformative learning, social inclusion

\section{Introduction}

In the age of globalization and super-diversity, our daily lives depend more and more on multiple interconnections across borders. Almost every country is involved in migration, which refers to multiple, circular, transnational movements across geographical spaces (Guo, 2015). As a result, many countries are becoming increasingly ethnoculturally diverse. Recognizing these global processes of

\footnotetext{
*Corresponding author: Sinela Jurkova, University of Calgary, Calgary, Canada, E-mail: sjurkova@ccisab.ca 
migration and transnational flow opens space for reconstructing the concept of intercultural competence. The evolution in intercultural competence research corresponds to the importance of developing skills and knowledge in order to behave and interact competently in a diverse society and workforce. For the past decade intercultural competence has revolved around different communication models (Bennett, 2008; Chen \& An, 2009; Deardorff, 2006; Gudykunst, 2005; Martin \& Nakayama, 2015), recipes for successful communication, and inventories (Hammer, Bennet, \& Wiseman, 2003) for assessing intercultural competence. Unfortunately, there is very little research exploring the experiences of transcultural learning and its impact on communication, interaction for organizational and community inclusion.

I propose using transcultural competence as transformative learning that will focus on examining and promoting paths for successful communication, interaction, and active participation in the global transnational environment. Transcultural competence as a learning activity can facilitate an individual's economic, sociocultural, and political adaptation to his/her host society for a vital and purposeful life for the society. Furthermore, its goal is to promote voluntary pluralism, global citizenship, and belonging by integrating different identities that relate to more than one ethnicity and culture.

It is therefore the purpose of this study to investigate how adults acquire transcultural competence through participation in different learning activities and how transcultural learning empowers personal growth and transforms an individual's perspectives. The discussion that follows is organized into four parts. First, it reviews a body of literature that informs this study. Next, it discusses the research design and data collection. Then, it presents the research findings, to be followed by more substantial discussions. Finally, I propose a model for developing competent and effective interaction among members of our very diverse society.

\section{Review of Literature}

This study is critically informed by a collage of literature relating to holistic concept of culture, transculturalism, and transformative learning. Conceptualizing culture, transcultural competence, and transformative learning provides information about their dialectic and dynamics, as well as their multidimensionality in analyzing the process of becoming transculturally competent.

Culture is a lens through which we communicate, interact, learn individually, and position ourselves in sociocultural context; therefore, first, I will outline the perspectives of Bennett (2009), Geertz (1973), and Trice \& Beyer (1993), which 
interpret culture as a context and a system of meaning and are fundamental in developing cultural competence. Understanding culture as a context in which perception and behavior occur, Bennett (2009) distinguishes between objective or "big-C" Culture and "little-c" subjective culture. Learning about Culture includes institutional, political, and historical circumstances that emerge from and are maintained by a group of interacting people. Subjective culture is the worldview of people who interact in a specific context: According to Bennett, a cultural worldview does not prescribe or determine the behavior of individuals who share the culture; rather, it constitutes the context in which perception and behavior occur.

In his eminent work, Geertz (1973) seeks the symbolic mediation of meaning embodied in ideas, attitudes, judgments, or beliefs. Geertz's interpretive holistic approach defines culture as "a pattern of meanings, a system of conceptions" (Geertz, 1973, p. 144), a "web of significance” (p. 5), a set, a vast geometry, a cosmos, a stratified hierarchy, a structure, and a frame. Similarly, a pluralistic view of culture and of an individual as a product of multiple cultural realities is further developed by Trice \& Beyer (1993). They describe cultures as collective, emotional, historical, symbolic, dynamic, and fuzzy. People's allegiance to their beliefs, values, and cultural practices develops primarily from their emotional needs (Trice \& Beyer, 1993). Accordingly, members of a culture rarely question their core beliefs and values, but if they do, their reaction is emotional. Cultures are historically based because they cannot be divorced from their histories and they do not arise overnight. The dynamics of culture incorporate contradictions, ambiguities, paradoxes that result from interaction and multiple subcultures.

The commonality between these scholars is their symbolic interpretation of culture. They see culture as a set of socially established symbols-a source of information through shared meaning, produced, perceived, and interpreted by members of a culture. This fabric of meaning guides individuals' actions and behaviors, and creates social structure (Geertz, 1973), systems of shared meaning and symbols (Trice \& Beyer, 1993), and the context in which behavior occurs (Bennett, 2009).

Secondly, the perspective of transculturalism provides the theoretical framework for this study. As a mode of being and learning where humans interact with each other in a culturally diverse environment, transculturalism offers new experience and intellectual generosity, a new way of seeing the world and understanding ourselves where ethics is at the crossroad of possibilities in human relations (Bakhtin, 1981; Epstein, 1999, 2009, 2012). The process of transculturation sees cultures as fluid, and places them in constant interaction with other cultures (Zhang \& Guo, 2015). Transculturation implies diffusion of multiple cultural identities as individuals cross the borders of various cultures and adopt them 
(Epstein, 2009). As such, transculture is the freedom of every person to live on the border of one's inborn culture or beyond it, adding another culture, moving to the transcendental realm that relates to all existing cultures, as they relate to nature (Epstein, 2009). Thus, transculturalism builds new configurations in the zone of interference that challenges the established and solidified identities; it is the next stage of ongoing human quest for freedom from determination, not abolishing cultural roots, but radically enriches cultural bodies.

Even the meaning of the prefix trans- brings the notion of dynamics, moving through space across the border (Kraidy, 2005) and expanding the limits beyond a single identity, switching between cultures and languages as a mode of being, having a sense of continuum, discourse, and transformation (Berry \& Epstein, 1999; Epstein, 2012). In this sense, transculturalism includes stabilizing or destabilizing effects, social conjunctions, historical conditions, and integration or disintegration of groups, cultures, and power. As an ideological perspective, transculturalism calls for cooperation, interaction, and exchange between communities and thus flexibility and an open mind on the part of individuals (Wilson, 2012). Transculturalism also expands the interdisciplinary field of study as new cultural and ethnic boundaries have emerged in our era of globalization, fostering multiple cultural interactions, attitudes, meaning making, and power formations (Brooks, 2007; Cuccioletta, 2001/2002; Kraidy, 2005; Lewis, 2002).

Slimbach (2005) proposes a map for transcultural development, including six broad categories: perspective consciousness, ethnographic skills, global awareness, world learning, foreign language proficiency, and affective development. The first proposition in Slimbach's map is recognizing universal human nature and potential as a prime identity for transcultural development. From this fundamental egalitarian acknowledgment, individuals start to discover and expand the range of alternative values, visions, and ways that others make sense of the world. Then the learners can see themselves and be able to move in and out of daily contexts where nationalities, gender, classes, languages, races, religions, and ideologies coexist in our era of intense economic, political, and cultural change. Knowledge and awareness of one's own cultural reactions, behavior, language, and that of the host society are needed competencies to succeed in a transcultural journey. This transcultural journey is a journey across multiple cultural spaces that are immersed, immediate and emotional (Slimbach, 2005) where learners bring knowledge from their own cultures to the process of learning and develop relationships and interactions across cultures.

The third body of literature that informs this study is research on transformative learning. Built on the foundational concepts of constructivist assumptions, humanism, and critical social theory, (Mezirow, 2000, p. 75) defined transformative learning as a process "by which we transform our taken-for-granted 
frames of reference ... to make them more inclusive, discriminating, open, emotionally capable of change, and reflective so that they may generate beliefs and opinions that will prove more true or justified to guide action". In Mezirow's view, the elements of critical reflection and dialog lead to a transformed frame of reference resulting in individual and social change. Frames of reference are structures of assumptions and expectations that frame an individual's tacit points of view and influence their thinking, beliefs, and actions. It is the revision of frame of reference in concerns with reflection on experience that is addressed by the theory of perspective transformation. A perspective transformation leads to a more fully developed frame of reference that often occurs either through series of cumulative transformed meaning schemes or as a result of an acute personal or social crisis (Mezirow, 1996). Learning occurs in one of four ways by elaborating existing meaning schemes, learning new meaning schemes, transforming meaning schemes, and transforming meaning perspectives (Mezirow, 2009).

Transformative process is indeed a complex discourse in which individuals reconstruct basic assumptions and expectations that frame their thinking, feeling, and acting. They develop concepts of the world and their selves based on perceptions that are contingent on various perspectives and interpretation. Meaning is seen not only as a cognitive event, but also as a social construct that is produced and changed in social interactions (Mezirow et al., 2009). The common ground between transculturalism and transformative learning is the idea of continuum: an on-going process of thinking, reflecting, and acting. This is the interconnection of knowledge, attitudes, and skills with responsible and liberatory action to make a difference in the world - to create a more socially just, equitable, inclusive, and peaceful world. A world, where each person takes multiple and varied actions individually and collectively. An action informed by inquiry, framing, positionality, dialog, and reflection that can be the catalyst for social justice, transformation, and inclusion. Transcultural learning as perspective transformation allows individuals located at the crossroads of cultures to switch between cultures as a mode of being in the world, as a quest for inclusion while considering common values, oppositions, tensions, and power in interactions (Jurkova \& Guo, 2018).

\section{Research Design and Data Collection}

To reiterate, this study examines the process of acquiring transcultural competence by adult learners and how transcultural skills and knowledge empower personal growth and transform their perspectives. Following Merriam (2014), the study employed qualitative research design, interpretive and constructive, 
comprised of semi-structured in-depth interviews as a primary method, focus groups, unstructured observation, and document analysis as secondary methods. The data collected through 21 face-to-face interviews with 11 Canadian-born and 10 immigrants - all adults, subsequently formed the foundational basis for the overall findings. Although the study includes both Canadian-born and immigrant participants, it was not designed to compare those two groups. Rather, the inclusion of participants from these two groups was necessary to broadly understand how different demographic characteristics (e.g., ethnic background, age, education) impact and distinguish the process of transcultural learning. Defining transcultural learning as a continuing learning process was the reason for selecting individuals who participated in one or more learning activities. This was an opportunity for participants to describe how different learning activities have impacted their transcultural competence.

Qualitative interviews were the primary method for data collection in this research because they offered the potential to capture a person's perspective of an event or experience (Marshall \& Rossman, 2011). They allowed us to investigate in critical ways respondents' comprehensions of their cultural experience and beliefs, the process of developing transcultural competence from their point of view. Particularly, in transformative learning, interviews can focus on the learner's story and experience to gain insight into the processes or outcomes of the learning, as well as to track learners' perspective changes or developmental progression over time (Cranton \& Hoggan, 2012). Thus, interviews served as a venue for understanding individual experience, transcultural skills, and perspective change. The interview questions were divided into several categories in relation to the research questions. The knowledge questions elicited participants' understanding about transcultural knowledge and skills that they have developed, the most beneficial ways of learning, and the resources that they have used to build their understanding. The second set of questions encouraged participants to share their experiences in acquiring transcultural learning: What motivated them to engage in these learning activities, and how had their perspectives changed and their lives been impacted?

Additionally, data collected from two focus groups informed about direct learners' opinions of participating and interacting in an event related to the issue of investigation: How transcultural learning enhanced personal transcultural development? The focus groups were productive for generating knowledge through dialog and contributed to achieving synergy in data collection. The observation provided information about how participants interacted during their learning activities and the document analysis shed light on the purpose, value, and the outcome of the diversity training program in which they participated. 
The concept of crystallization is more relevant to this qualitative inquiry and to the research phenomenon. With multidimensionality of approaches, correlations, methods of data collection, and analysis, crystallization provides deeper understanding of the topic (Ellingson, 2009; Richardson, 2000). Complexity and continuum, as principles of crystallization, are consistent with the distinctive characteristics of transculturality in this discourse. The continuum is achieved through blended approaches for meaning-making and representation. The complexity of the research embodied description and interpretation of participants' understanding, knowledge, and learning process construction.

\section{Report of Findings}

The research findings reveal a holistic process that involves the cognitive, affective, and social dimensions through which individuals develop transcultural competence. Examining and reflecting on their individual experiences, participants outlined intrinsic and extrinsic factors that motivated them for developing transcultural qualities in relation to the need of personal growth, family relationship, and adaptation to an increasingly ethno-culturally diverse society. Participants also constructed transcultural competence as a multidimensional transformative process that challenges their taken-for-granted frames of references and expanding the horizons of their world views.

\subsection{Cognitive Dimension}

The cognitive aspect entails participants' curiosity, meaning construction about different languages, cultures, and values, as well as their exploring and reasoning of their own biases and past experiences. Driven by their curiosity many participants discovered different opportunities to learn about cultures and develop their knowledge, starting from childhood and continuing systematically as part of their professional career. For example, one participant explained that his interest in exploring cultures started in his childhood, reading National Geographic magazines. For another, reading stories about different places in the world in her early age nourished her curiosity that led to a degree in history, traveling and working in different countries, and having a professional career in cultural education. Once on their journey, participants gradually developed transculturally by reading, learning, researching, and practicing, all the while questioning and examining their own views and beliefs. Jordan called this a mirror: 
It is like a mirror where we examine ourselves asking why I do what I do. Why do I feel that? Why do I say things that I don't like? How can I overcome them? Having the answers, then, the next step is how we approach and communicate with others. (Jordan)

Transcultural learning intersects with self-awareness of and self-reflection on self's own biases, while recognising and understanding others without judging and comparing: "it is being aware of your biases, constantly checking and reaffirming, able to understand them, put those aside, step up forward, and stay open-minded." (Jim)

Several participants described transcultural competence as knowledge about different cultures, history, and what happens around the world:

We do not always understand the protocol in any cultural tribe; we have to try in the best ability to learn what the need of some of these cultures might be. But really, I think it's about being open-minded, listening and valuing differences, be open and honest. (Margaret)

Transcultural competence is to understand where others come from, having world knowledge about what is happening to other countries and how this may affect people, especially people who come here, like refugees, migrants. (Rose)

Additionally, participants recognized speaking different languages as essential skills for transcultural competence. For example, Nadia studied Spanish and conducted research in South America. Speaking Spanish helped her to better understand the culture there and communicate freely with local people. Likewise, Jim noted that he always tried to learn words from different languages and to use these words, stating that, "even a simple greeting in a different language breaks the ice, builds trust, and eases communication and interaction."

A French-Canadian spoke about how her French accent created tension in interactions in an English-speaking province, making her feel isolated and discriminated against. Despite her willingness and readiness to learn, she struggled to build flexibility in crossing from one culture to another because people opposed her accent:

I have experienced people being rude to me just because of my French accent, called me a 'stupid girl,' blamed me for not knowing my official language. The lack of others' understanding of my culture made me struggle. (Marie)

Discussing cognitive aspect of transcultural competence, all participants emphasized that such knowledge is always emotionally connected by demonstrating sensitivity and support, openness in approaching other cultures and communicating with people. The ability to take the perspective of others requires cultivating of emotional skills for empathy that will navigate individuals flexibly across different cultures. 


\subsection{Affective Dimension}

The emotional aspect functions for developing and demonstrating humility, kindness, empathy, and respect to others. As one participant stated, "being able to empathise and support, with conformity, with human rights and dignity is the essence of transcultural competence" (Okeo West).

Being in other's shoes and having the flexibility to change perspectives are skills considered valuable by most of interviewees. Anaya, an immigrant who worked in another country before coming to Canada and who had significant exposure to different cultures, explained:

Every time when I meet someone different or see something different, I put myself in other's shoes, and I found it makes me a better person. I was lucky to be surrounded by people with open hearts and minds, and I learned a lot from them. (Anaya)

Anaya also commented that she uses this skill successfully in her work and it builds trust with her clients. Others also agreed that learning through being in other's shoes, evoke emotions and make people imagine how they may feel in a different position. For example, Lucila uses role-play in her program to evoke emotions and found this an important transcultural learning approach for understanding cultural differences without opposing to them.

A Canadian-born English teacher who has lived in different countries explained that she took many cultural courses as part of her degree. This, along with her compassionate and sensitive character, enabled her to strengthen her transcultural competence. She stated:

Hearing tragic stories from immigrants hit me; I accept them more from emotional perspective, very sensitively. I had moments in class near to tears listening to stories from my students that hit me so much. (...) It is great to share and listen to these stories, as many people do not have an idea about what life could be like if you are not born and raised in a country like Canada. (Rose)

Participants also talked how mentors, emotional supporters, and peers played essential roles in their transcultural journey. Some found this emotional support in their families and colleagues, others through community activities and in their neighborhood. Celine, who was single and felt lonely, found this support in a church:

In a church or in the community, you have the need to be loved, to share your story, to feel accepted, and belonged. In my church community, I found love, spirit and compassion. (Celine) 
Additional to affective dimension, participants also acknowledged the ability to recognize different cultural identities without betraying their own culture as insignificant for creating a new transcultural community. For example, Lisa had lived in several countries before she settled in Canada. She does not see herself as a hybrid of Chinese and Canadian cultures; rather, she identifies values from many cultures that intersect nationality, profession, social status, gender, age, and family positionality. Or Andrew, who was born in Nigeria, studied in the UK, and lived in Canada, reflected on his own cultural label thus:

I am a person who complies with many cultural identities and incorporates values from all, but it doesn't really bother me. I enjoy having all my roots, talk about, learn more and interact with people. Should I call myself transcultural? (Andrew)

Participants in the second focus group agreed that transculturality is an advanced stage of cultural development that goes beyond the restrictions of traditional cultures (e.g., ethnic, national, racial, religious, gender, sexual, and professional) and broadens cultural boundaries. The most significant finding is that participants connect transcultural learning to identity freedom - the freedom to distance from or integrate into other cultures due to flexibility and reflexivity, empathy and interaction, which encourages an alternative mode of thinking, an ability to navigate through and transact in multiple cultures. The ability to move beyond the politics of location, without opposing differences, keeping the connection with cultural roots but not obsessed by them, differs transcultural from intercultural context.

The emotional stories shared by participants during the interviews confirmed the importance of considering affection in developing transcultural competence, because it is only with open hearts and open minds that people can move forward. Indeed, they do not separate intellectual skills from their emotions, feelings, and attitudes. As part of the emotional aspect of learning, they discussed how they developed this competence, interacting with people, while cultivating humility and respect for varied and complex human experiences, recognizing their own limitations, and ultimately finding the ability to accept individuals as unique, without opposing them. In the interviews, participants talked about how demonstrating sincerity, a genuine interest in others, and reflecting on their own life cultivated their empathy, compassion, companionship, collaboration, and wisdom.

\subsection{Social Dimension}

The social dimension in transcultural competence is related to a conscious effort and determination to understand others and interact with them in social, cultural, 
and professional spheres. Traveling and immersing themselves in different cultures became a source for developing cultural knowledge for almost every one of the participants who emigrated, worked, or studied abroad. For non-Canadianborn participants, leaving their home country was a starting point for transcultural learning, including learning languages and different ways to communicate and behave, all of which required effort and consistent learning.

The data reveal that both immigrant and Canada-born participants acknowledged the significance of listening skills in guiding them to better understand others and interact respectfully, especially for those participants who work as service providers and have very diverse clients. One participant, born and raised in Taiwan of China who came to Canada as a university student, noted that she observed and listened a lot: "I didn't speak much, I learned a lot from listening to other people" (Shan).

A Canada-born Canadian who works with diverse clients as a service provider shared how she develops her transcultural learning trough interaction. She explained:

I traveled a lot from a very young age. I love meeting people and I am curious about everything. I just go to people. When they are new here, don't wait for them to come to you-you go to them, you know the language, you know how to do things, they may not. Go to them, talk, ask questions, and spend time with them. Be curious, not judgmental, don't assume, be a really good-question-asker and listener. (Sophie)

Similarly, Jim and Valerie shared their personal stories about how positive exposure to different cultures and cultural interaction from an early age affirm and expand their transcultural competence. The situation was opposite for Arthur and Sophie - they talked about personal transformation from biased ethnocentric behavior adopted in the families to a new person consciously going beyond the preconceived box to explore, learn, and practice ethno-relative ways of thinking and interacting with people. Sophie noted:

My parents influenced my understanding of other people's culture and it turned me into a kind of racist child. Once, I said something loudly in class that I heard from my mom which came to be very racial. I was troubled and felt very confused. The fact that I still remember this explains how significant this negative experience was for me. (Sophie)

However, this disjuncture prompted a positive personal transformation that further motivated Sophie, as well as Arthur, to develop their transcultural learning, to be exposed to different cultures and interact, and further became educators and promoters for transcultural learning. From a transcultural perspective, Arthur's and Sophie's experiences demonstrate that it is possible to overcome one's obsession of inherited or given culture and expand one's cultural interactions and 
relationships. Holistic learning indeed develops knowledge that is constructed by the context in which a person lives.

Empowered with transcultural knowledge, a majority of participants see themselves as active agents for promoting learning to family members, colleagues, and their community as a path for navigating successfully through the dynamics of cultures. They described transcultural competence as a foundational process that comprises personal consciousness, self-determination, and courage to initiate collective action. Furthermore, they recognized the importance of transcultural learning and acted as educators, mentors, and leaders by challenging existing practices and promoting inclusion in the workplace and in society. Then, in holistic learning contexts, participants find meaning, identities, and purpose, build empathy, create sense of commonality and humility through connections to their communities and to the world.

\section{Discussion}

Connecting transculturalism with participants' experience of learning offers a lifelong path for humanity's progress and community inclusion. Overall, in this discussion the participants' perspectives about the phenomenon of the study support the literature. Transculturality is constructed as a sum of qualities relating to being a transcultural individual, including an ability to see the world in a way that relates to others with limited prejudicial thinking, to transcend one's own culture to understand and see the merits of another culture, and to bring people of different backgrounds together. Participants' open-mindedness and receptiveness to the other are due to their capacity to share an experience of life that brings individuals together, being emotionally supportive, curious to learn and explore, to listen and interact. Transculturation, then, is designated as a holistic process of learning and exchange, from which a new reality emerges, transformed, and complex. Taking a transcultural journey, individuals transform themselves and become agents of change in their own environment. Participants emphasized variables, including self-awareness, authenticity, communication, building rapport, trust and empathy, collaboration, and empowerment. Enriched with transcultural knowledge, participants moved beyond their own cultural socialization, expanded their cultural horizons, and, furthermore, contributed their knowledge for greater effectiveness and community inclusion.

The research findings demonstrate that developing transcultural competence is a holistic, multidimensional process that requires the development of cognitive knowledge together with an ability for emotional attachment and support, interaction and engagement in real cultural interactions. The multiple transcultural 
dimensions are outlined in Table 1 according to three categories-cognitive, affective, and social. For example, the cognitive dimension comprises of openmindedness, knowledge about the world, proficiency in more than just the language of host society, awareness, and reflectivity. This dimension also encompasses the importance of analytical skills and the ability to apply different cultural perspectives in a transcultural context. The affective dimension relates to humility, empathy, sensitivity, and freedom in constructing and choosing multiple identities without opposing each other. The social dimension refers to real cultural exposure, communicating and interacting flexibly and comfortably in different cultural settings, maintaining positive relationships and act as agents of change.

In the holistic process of transcultural learning, learners invite their previous and current knowledge, individual observations, experiences, feelings and interaction to the process of cultivating relationships across cultures, developing skills and awareness, social sensitivity, and humility. Participants immigrants and native-born, discovered different paths and opportunities for transcultural learning that transformed them. In this sense, differences between the two groups do not contradict them, neither impact negatively the learning process, societal engagement and belonging. Rather, this study acknowledges transcultural competence as vital for all members of our society, without differentiating between them based on ethnicity, race, religion, and social privilege or disadvantage.

Connecting these findings with transcultural theories led to the construction of a holistic learning model (Figure 1) that involves inquiry, framing, positionality and progressing to dialog, reflection, and competent action. Moreover, I argue that the common ground between transcultural learning and lifelong learning is the idea of continuum, an ongoing holistic process of thinking, reflecting and acting, that includes cognitive, emotional, and social aspects of learning.

Through interconnection of knowledge, attitudes, and skills, with responsible and liberatory action the transcultural learning model can create a more socially just, equitable, and inclusive world. In this path, inquiry is a desire and willingness to know, to ask, to find out, and to learn. The practice of inquiry leads us to engagement with others. In transculturalism, inquiry is exploring universal and unique human nature, experiences, and potential, discovering the ways that others make sense of the world (Slimbach, 2005). Likewise, this is the notion of experience in transformative learning-prior learners' experiences and what they learn about themselves and the world when they participate in learning activities. Whereas participants engage in such activities and interact, sharing their experiences also make them aware of the frame of reference from which they see the world. Framing is a knowledge construction across cultural dimensions, time, and space, which fosters transformation in learning. Consequently, in transculturalism, framing is distancing from one culture in order to understand it and transcend its boundaries. 
Table 1: Holistic process of transcultural learning.

\begin{tabular}{|c|c|c|}
\hline \multicolumn{2}{|c|}{ Holistic dimensions } & Description \\
\hline \multirow[t]{6}{*}{ Cognitive } & Open-mindedness & $\begin{array}{l}\text { - Genuine interest and curiosity to learn, explore, } \\
\text { experience, and apply different cultural perspectives } \\
\text { - Openness to a more complex understanding of the } \\
\text { world and oneself, accepts others without comparing } \\
\text { and judging }\end{array}$ \\
\hline & World knowledge & $\begin{array}{l}\text { Knowledgeable about cultures, ethnicity, history, } \\
\text { geography, religions, politics, sociology } \\
\text { - } \quad \text { Understanding culture in a holistic way }\end{array}$ \\
\hline & Language proficiency & $\begin{array}{l}\text { - } \quad \text { Speaking the language of the host society } \\
\text { - Using different spoken/written/nonverbal languages }\end{array}$ \\
\hline & Analytical skills & 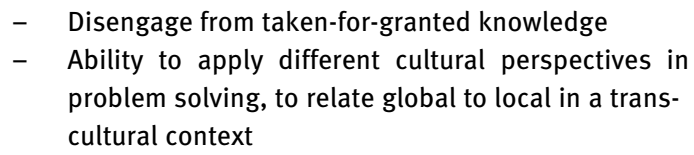 \\
\hline & $\begin{array}{l}\text { Awareness, } \\
\text { self-awareness, and }\end{array}$ & $\begin{array}{l}\text { - Awareness about own and other's perceptions, } \\
\text { reactions, differences, and interpretations }\end{array}$ \\
\hline & self-reflectivity & $\begin{array}{l}\text { Questioning own biases, avoiding stereotypes, } \\
\text { judgmental attitude, resist oppression }\end{array}$ \\
\hline \multirow[t]{4}{*}{ Affective } & Empathy and sensitivity & $\begin{array}{l}\text { - Capacity to demonstrate emotional support, } \\
\text { sincerity, patience, and joy within a specific cultural } \\
\text { context } \\
\text { _ Capacity to "put oneself in another's shoes" }\end{array}$ \\
\hline & Humility & - Ability to recognize own limitations \\
\hline & & $\begin{array}{l}\text { - Respect toward diverse others and ability to deal with } \\
\text { emotions } \\
\text { - Recognize that beside the diversity people share } \\
\text { common human potentials and experience }\end{array}$ \\
\hline & Transcultural identity & $\begin{array}{l}\text { - } \quad \text { Freedom from one predetermined or hybrid culture } \\
\text { - } \quad \text { Feel comfortable with multiple identities, flexibly } \\
\text { shifting, without abandoning own cultural roots } \\
\text { - Identity as continuum, mirroring the dynamics of } \\
\text { cultures }\end{array}$ \\
\hline \multirow[t]{6}{*}{ Social } & Cultural exposure & $\begin{array}{l}\text { - } \quad \text { Life experience of different cultures } \\
\text { - Willingness to participate in different cultural events } \\
\text { and unfamiliar settings }\end{array}$ \\
\hline & Communication skills & - Good listener and question asker \\
\hline & & $\begin{array}{l}\text { - Ability to apply and interpret different cultural styles, } \\
\text { etiquettes, and expressions } \\
\text { - } \quad \text { Ability to engage in meaningful dialog and mutual } \\
\text { self-disclosure }\end{array}$ \\
\hline & Engaging in interaction & $\begin{array}{l}\text { - Ability to maintain positive interpersonal } \\
\text { relationship }\end{array}$ \\
\hline & & $\begin{array}{l}\text { - Flexibility, confidence, and comfort in navigating } \\
\text { through different cultures }\end{array}$ \\
\hline & & $\begin{array}{l}\text { - Ability to motivate and inspire others for trans- } \\
\text { cultural learning }\end{array}$ \\
\hline
\end{tabular}


Table 1: (continued)

\begin{tabular}{ll}
\hline Holistic dimensions & Description \\
\hline Social $\quad$ Acting as agent of change - & Advocate for and promote transcultural learning. \\
& \\
& Serve as mentors and educators \\
- & Taking leadership role for change in organization and \\
& in communities \\
\hline
\end{tabular}

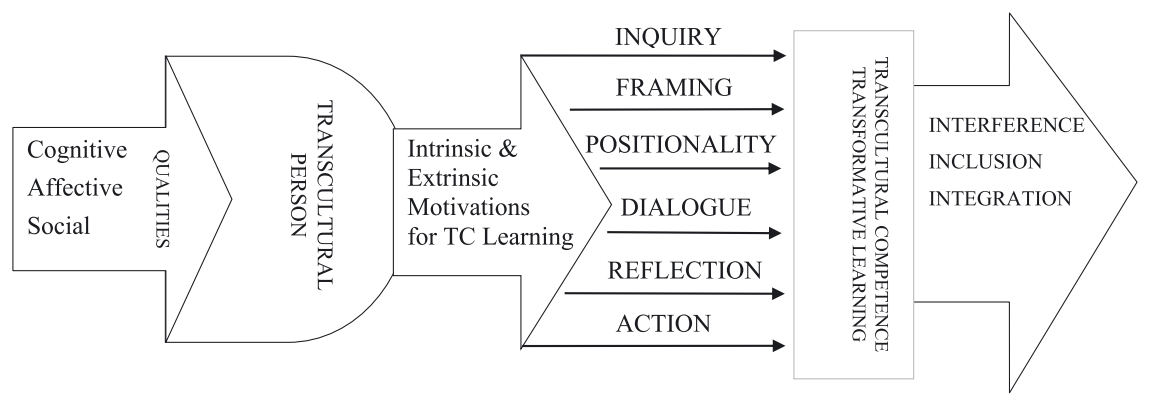

Figure 1: Transcultural model for personal development and social impact.

Positionality constitutes the next standpoint in transcultural learning - a place from which to view and make sense of the world around us. It assumes that socially constructed hierarchies based on race, class, gender, nationality, religion, age, and physical abilities, among others, position us socially, geographically, politically, symbolically, and materially in relation to each other, to structures and configurations of power. Differences in power and positionality are evident when one engages in a dialog.

The process of dialog invites participants to imagine, experience, and engage creatively with points of view, ways of thinking, being, doing, and beliefs. For Bakhtin (1981) and Epstein (2012), dialog is a path for cognition of human being, a self-awareness, and discovery of others. Dialog becomes the medium for critical reflection to be put into action where experience is reflected on, assumptions and beliefs are questioned, and habits of mind are ultimately transformed. Then, an action informed by inquiry, framing, positionality, dialog, and reflection can be the catalyst for social justice, transformation, and inclusion.

The transcultural path is multidimensional, complex, and dynamic. The stages are non-linear, they may overlap, may create contradictions, and repeat during this transcultural transformative journey of teaching and learning. Additionally, each of those critical ingredients corresponds to the cognitive, affective, 
and social dimensions of learning. There is a common ground between transformative learning and transcultural theories in terms of how to view the process of developing transcultural competence: a positive and constructive deconstruction, involving ongoing change and action in sociocultural surroundings, reaching new horizons of knowledge and implementation. As such, transcultural learning model reflects the cultural dynamics of the society, transnational movements, local and global changes.

\section{Conclusions and Implications}

The transformative model of developing transcultural competence aligns with the new realities and demands of a rapidly diversifying and transnational world characterized by new mobility patterns, interconnectedness, and post-ethnicity (Fleras, 2019). Furthermore, the transcultural notion of understanding cultures as self-differentiated but mutually involved, without isolating them from each other corresponds to the humanistic interferential model in the study of cultures proposed by Bakhtin (1981), Berry \& Epstein (1999), and Epstein (2012). Integrating different identities and connecting the global with the local, transculturalism is a learning commitment that facilitates communication, interaction, and sociocultural adaptation in a dynamic society recognizing different worldviews. This study offers a theoretical perspective and a vision that aim at dissolving cultural and ethnic binaries and the duality of opposing local to global, national to international, particular to universal, and mainstream to newcomers, us to them. As such, it could apply to communications studies and education where competent educators and learners will be able to engage in dialog and implement diverse forms of learning, communicating, and interacting, while building trust and creating safe space for participants.

This study also sheds new light on individual development and organizational growth. Implementing the model for transcultural competence in the workplace will stimulate better usage of talents and will facilitate sociocultural adaptation and foster an inclusive society. A transcultural worldview will help international businesses to bridge gaps between local norms, standards, perceptions, and working habits. Furthermore, human resource departments can establish competent hiring practices for recruiting, training, and retaining international talents. Transculturally competent workers and leaders with cognitive, affective, and social knowledge will be more adaptable and flexible on local and global stage, better prepared to face technological progress in all spheres. 


\section{References}

Bakhtin, M. (1981). The dialogical imagination: Four essays. Austin: University of Texas Press.

Bennett, M. (2008). On becoming a global soul. In V. Savicki (Ed.), Developing intercultural competence and transformation: Theory, research and application in international education (pp. 13-31). Sterling, Va: Stylus.

Bennett, M. (2009). Defining, measuring, and facilitating intercultural learning: A conceptual introduction to the intercultural education double supplement. Intercultural Education, 20(1), S1-S13.

Berry, E., \& Epstein, M. (1999). Transcultural experiments: Russian and American models of creative communication. New York: St. Martin's Press.

Brooks, A. (2007). Reconceptualizing representation and identity: Issues of transculturalism and transnationalism in the intersection of feminism and cultural sociology. In T. Edwards (Ed.), Cultural theory: Classical and contemporary positions (pp. 183-211). London: UK: Sage Publications.

Chen, G., \& An, R. (2009). A Chinese model of intercultural leadership competence. In K. Deardorff (Ed.), The Sage handbook of intercultural competence (pp. 196-208). Thousand Oaks, CA: Sage Publications.

Cranton, P., \& Hoggan, C. (2012). Evaluating transformative learning. In E. Taylor, \& P. Cranton (Eds.), Handbook of transformative learning: Theory, research, and practice (pp. 520-535). San Francisco, CA: John Wiley \& Sons.

Cuccioletta, D. (2001/2002). Multiculturalism or transculturalism: Towards a cosmopolitan citizenship. London Journal of Canadian Studies, 17(1), 1-11.

Deardorff, D. (2006). Assessing intercultural competence in study abroad students. In M. Bryam, \& A. Feng (Eds.), Living and studying abroad: Research and practice (pp. 232-256). Clevedon, UK: Multilingual Matters.

Ellingson, L. (2009). Engaging crystallization un qualitative research: An introduction. Thousand Oaks, CA: Sage Publications.

Epstein, M. (1999). From culturology to transcultural. In E. Berry, \& M. Epstein (Eds.), Transcultural experiments: Russian and American models of creative communication (pp. 15-30). New York: St. Martin's Press.

Epstein, M. (2009). 12. Transculture: A broad way between globalism and multiculturalism. The American Journal of Economics and Sociology, 68(1), 327-351.

Epstein, M. (2012). Transformative humanities: A manifesto. London, UK: Bloomsbury Academic.

Fleras, A. (2019). 50 years of Canadian multiculturalism: Accounting for its durability, theorizing the crisis, anticipating the future. Canadian Ethnic Studies, 51(2), 19-59.

Geertz, C. (1973). The interpretation of cultures: Selected essays. New York: Basic Books.

Gudykunst, B. (2005). Theorizing about intercultural communication. Thousand Oaks, CA: Sage Publications.

Guo, S. (2015). The changing nature of adult education in the age of transnational migration: Toward a model of recognitive adult education. In S. Guo, \& E. Liang (Eds.), Transnational migration, social inclusion and adult education. New directions for adult and continuing education (Vol. 146, pp. 7-17). San Francisco, CA: Jossey-Bass.

Hammer, M. R., Bennett, M. J., \& Wiseman, R. (2003). Measuring intercultural sensitivity: The intercultural development inventory. International Journal of Intercultural Relations, 27(4), 421-443. 
Jurkova, S., \& Guo, S. (2018). Connecting transculturalism with transformative learning: Toward a new horizon of adult education. Alberta Journal of Educational Research, 64(2), 173-187.

Kraidy, M. (2005). Hybridity, or the cultural logic of globalization. Philadelphia, PA: Temple University Press.

Lewis, J. (2002). From culturalism to transculturalism. Iowa Journal of Cultural Studies, 1(1), 14-32.

Marshall, C., \& Rossman, G. (2011). Designing qualitative research (5th ed.). Thousand Oaks, CA: Sage Publications.

Martin, J. N., \& Nakayama, T. K. (2015). Reconsidering intercultural (communication) competence in the workplace: A dialectical approach. Language and Intercultural Communication, 15(1), 13-28.

Merriam, S. (2014). Qualitative research: A guide to design and implementation (3rd ed.). San Francisco, CA: Jossey-Bass.

Mezirow, J. (1996). Contemporary paradigm of learning. Adult Education Quarterly, 46(2), 158-172. Mezirow, J. (2000). Learning to think like an adult: Core concepts of transformation theory. In J. Mezirow, \& Associates (Eds.), Learning as transformation (pp. 3-34). San Francisco, CA: Jossey-Bass.

Mezirow, J. (2009). Transformative learning theory. In J. Mezirow, E. Taylor, \& Associates (Eds.), Transformative learning in practice: Insights from community, workplace, and higher education (pp. 18-31). San Francisco, CA: Jossey-Bass.

Mezirow, J., Taylor, E., \& Associates. (2009). Transformative learning in practice. Insights from community, workplace, and higher education. San Francisco, CA: Jossey-Bass.

Richardson, L. (2000). Writing: A method of inquiry. In N. Denzin, \& Y. Lincoln (Eds.), Handbook of qualitative research (2nd ed., pp. 923-943). Thousand Oaks, CA: Sage Publications.

Slimbach, R. (2005). The transcultural journey. Frontiers: The Interdisciplinary Journal of Study Abroad, 11(1), 205-230.

Trice, H., \& Beyer, J. (1993). The cultures of work organizations. Englewood Cliffs, NJ: Prentice-Hall. Wilson, S. (2012). Multiculturalism and transculturalism: What can we learn from Vice Versa magazine (1983-1996). International Journal of Canadian Studies/Revue internationaled'étudescanadiennes, 45-46, 261-275. 